\title{
Industry 4.0 readiness: the impact of digital transformation on supply chain performance
}

\author{
Egor V. Dudukalov ${ }^{1}$, Irina V. Terenina ${ }^{2}$, Marina V. Perova ${ }^{1}$, and Denis Ushakov, ${ }^{3, *}$ \\ ${ }^{1}$ Russian Presidential Academy of National Economy and Public Administration, South-Russian \\ Institute of Management, Rostov-on-Don, Russia \\ ${ }^{2}$ Don State Technical University, Rostov-on-Don, Russia \\ ${ }^{3}$ Suan Sunandha Rajabhat University, Bangkok, Thailand
}

\begin{abstract}
In the context of Digital Economy the usage of information and communication technology to promote commercial operations has grown significantly with the advent of electronic business and networking systems. This research focuses on the new generation technologies and on communications between all supply chain components. The study enable Russian and Thai retail supply chain administrators and market leaders (including policy makers) to share their expert opinion about impact of digital transformation on supply chain performance. Once each organization affirmed its commitment to be engage in the interview, analytical conclusions were made on the basic of semi-structured open discussions and surveys of 18-36 employees from each organization which were combined in such a way as to present a complete profile of the organizations readiness to Industry 4.0 strategy. 236 semi-structured open interviews focused on a few topics and keywords have been performed. In fact, five generalized qualitative interviews (profiles) present the analytical evidence from five leading brands. This approach helps to consider more fully how they perceive and understand digital transformation. The purpose was to gain a rich basis of the interviewed person's content and this approach is quite well adapted to analyses. The research implemented the quantitative methodology throughout using the named data and had been treated with SPSS statistical tool for hypotheses validation. As the result statistically evidenced presence of a relationship between digitalization, the Industry 4.0 technologies and supply chain performance.
\end{abstract}

\section{Introduction}

The value of digitalisation and Industry 4.0 technologies has evolved dramatically in supply chain management in quest for competitive edge. Industry 4.0 facilitates convergence and cooperation among various supply chain players and fast exchange of information. Supply chain participants are able now to simplify repetitive work, Internet of things contributes to cost savings and service changes in many functional areas including storage, inventory control, ordering, customer service, development scheduling and supplier operations. Recent players on the industry are implementing digital innovation like digital

\footnotetext{
*Corresponding author: denis.us@ssru.ac.th
} 
sales control, e-procurement, e-payments, and partnerships to improve customer experience. At the same time Industry 4.0 technologies, such as cyber-physical systems, Internet of things, on-demand availability of computer system resources, cognitive computing etc. will provide fundamental change in the future but some pieces of the Industry 4.0 technologies are available and affect supply chain right now. In this study we will try to determine how big this impact is and whether companies are ready for the Fourth Industrial Revolution.

Readiness for these revolutionary innovations is significant as it leads to better consistency of choices and enhanced efficiency of supply chain. In order to create value, firm's emphasize responsive sourcing and delivery in the supply chain beyond the effectiveness of internal operations. Suppliers' flexible networks are used by companies to deliver a range of products. For dealing with uncertainty and complexity linked with the changing behavior of customers, a crucial competitive factor is supply flexibility [1].

In the market climate and not to mention in its logistics supply chain management, Internet of things is an evolving phenomenon. As the demands of the supply chain are growing, various processes and manual handling of information must be removed. The Industry 4.0 technologies help businesses to focus on their supply chain plans and discover innovative opportunities to collaborate with other organizations. It can be reached because Industry 4.0 represents a smart manufacturing networking concept where machines and products interact with each other without human control [2].

Implementation of market strategies focused on innovations provides a platform that integrates diverse actors, such as vendors, business associates and clients. However, a variety of difficulties (skills deficit and lack of awareness); high implementing costs; lack of security; unequal partner benefits (adoptability differences); and difficulty in achieving change goals can appear.

The purpose of the analysis is to assess the effect of digitalization and Industry 4.0 technologies implementation on the supply chain performance in context of the Digital Economy. We conducted the research with the following objectives: (a) Identify the supply chain processes effect of the digitalization and Industry 4.0 technologies. (b) Assess the influence of the convergence between internal and external supply chain electronically activated actors. (c) Recognize the issues confronting supply chain organizations and their supply chain participants in the process of technology powered network transactions. (d) Determine how infrastructural conditions and capabilities in the area of information technology impact the management of the electronic supply chain. (e) Propose suitable and sustainable Industry 4.0 management and supply chain enhancement techniques.

As a result, we put forward two hypotheses that we intended to confirm or reject in the course of studying the empirical data:

H1: There is statistical evidence of a relationship between digitalization and supply chain performance.

$\mathrm{H} 2$ : There is no statistical evidence of a relationship between Industry 4.0 technologies and supply chain performance.

Given that the study was conducted in Thailand and Russia, we suggested that it logical to formulate H2 in presented way, relying on [3], according to which in Thailand organizations are not taking interest in making these policies and as a result their Industry 4.0 is facing different challenges. They are stick to old and traditional business techniques and facing adverse consequences. These problems are not only confined in Thailand, many surrounding developing (including Russia) and under developed countries are facing these problems.

In highly developed countries changes in the manufacturing sector are pressuring corporations to follow a new model of production called "agile growth". It is seen as a successful tactic in a business that is highly competitive with evolving customer 
expectations and drastic changes in efficiency. The key role of Industry 4.0 is to simplify networking across the Internet. Industry 4.0 is described as a meta concept to improve development further and to build value structures by connecting the physical world with the digital environment [4].

Due to the fact that technological innovations cannot be effectively implemented in the absence of appropriate social needs, we considered it possible not to take into account certain technological limitations, since technology transfer and the development of global innovation networks [5] currently allows us to catch up with the existing technological gap on the principle of "catch-up development". At the same time, Russia and Thailand are approximately on the same level in many digital and technology indexes, being in the top third of the leading countries in the world or being very close to it, for example, taking 48 and 51 places, respectively, in The Network Readiness Index 2020 [6]. Therefore, it is much more important to understand the impact of digitalization and Industry 4.0 technologies on supply chain performance, as well as to assess the readiness for Industry 4.0 in the organizations of these two countries.

\section{Literature Review}

\subsection{Impact of digital transformation}

The literary analysis reflects on concepts of Industry 4.0 in the supply chain, policy growth and change management. Technology and creativity enable businesses to work differently and deliver uniquely timely goods and services, providing flexibility increases towards the changing requirements of the market related for improving the supply chain performance [1].

[7] indicates that Internet of things infrastructure has helped to build methods for strengthen activities in the supply chain. Customer responsiveness is improved and consumers' retention, sales and income increases are boosted. [8] agrees that supply chain management increases the productivity and efficiency of a business. The financial performance of corporations and the depth and complexity of their supply chains is really associated. Through implementing creative forms of transacting business, value produced affects suppliers, intermediate manufacturers and customers alike.

[9] describes the supply chain as the flow of goods, knowledge, money and services from suppliers of raw materials through plants and warehouses to customers. The supply chain includes domestic and foreign partners in multiple locations. Multiple trade partners from vendors, producers, dealers and consumers provide the supply chain control of products and services. The purpose is to enhance inventory management, company operations and customer care to eliminate unhealthy environments and threats.

\subsection{Sustainability issues of supply chain}

Sustainability issues of supply chain management in Industry 4.0 dedicates works [10-12]. The idea of ensuring sustainable development in them is based on the concept of the circular economy concept, which has originated from both industrial ecology and environmental economics. Practitioners often consider it as a way to overcome the limitations of linear production and consumption models for increasing resource use efficiency. The circular economy has been introduced to achieve a better balance between the economic aspect and the environmental and social aspects of sustainability. As new technologies emerge, novel business models can orient organizations toward enhancing sustainability outcomes through circular economy principles. 
However, in this statement interoperability issues that control the links were not taken into account. The flow of knowledge in logistics and supply chains is as critical as the flow of products, resources and people. Therefore, high inventory turnover is expected for the retail sector which needs prompt knowledge transmission in the supply chain. [13] emphasizes that knowledge consistency and scheduling provide effective decision-making and simplify reaction to consumer needs. According to [14] manufacturers are still trying to manage stock levels and ensure the correct items are accessible at the store level in the right amounts. Store inventory outputs need to be avoided and consistent stock supply maintained to sustain consumer loyalty.

[15] stresses that the operating structure of the organization must achieve large competitive and strategic goals which need to be expressed in quality, pace, confidentiality, flexibility and cost improvement steps. [15] says the essence and requirement of the goods of the business must be taken into consideration when developing a supply chain. An automated IT structure with open buyers and vendors supplying inventory details and modified demand levels, allowing it easier to enforce supply pulling and, therefore, not drive up inventory in expectation of potential demand is important. In the supply chain, timely changes are needed for successful and productive inventory refill.

\subsection{Organizational and operational agility}

The producers must continually upgrade goods and services in an increasingly digital world and build a competitive edge. In company and industry, they must be agile to build value and differentiate themselves from the competition [16]. The agility of the organization depends on the information, know-how and inventiveness of its members [17]. Organic agility requires responsiveness, pace, versatility and abilities. Moreover, there is constant creativity in organizational agility. New prospects, including automation of added nonvalue activities through equipment and agile applications, are created by technological advancement in the manufacturing world. This allows businesses to easily respond to environmental shifts and variations.

Through extending the concept of operational organizational agility, agility is the capacity to respond to change that is achievable by relentless creativity and the use of scalable and re-configurable technology [18]. Agility is often associated with the fast and accurate electronic document circulation between human and the establishment of a relevant and real-time information system exchanging information without human beings. Lean development is also the first phase in improving of process management both in manufacturing and post-production, both in identifying and eliminating waste sources. Lean development coupled with efficient technological usage contributes to operational stability and increased resource performance [19]. The core concepts that enable the development of Industry 4.0 companies to work in the world, are organizational and operational agility. It also makes for quicker and more effective decision-making. Operating agility helps them to plan for consumer needs efficiently and effectively with computers and devices.

\subsection{Barriers to implementing digital transformation in companies and segments}

In every market, businesses face a broad variety of obstacles in digital change implementation and management. Organizational, strategic, cultural or administrative problems may be [20]. This barrier literature reflects on four dimensions: societal, operational, institutional and strategic. All these aspects are grouped into a multiplicity of parameters that the literature on the topic of digital transformation posed. 
Research in the field of supply chains in separate economic sectors and countries may be of particular interest. For instance, studies such as [21-23] provide insight into the situation in the automotive industry, while [24] demonstrates best practices in the agriculture supply chain. In our research work, we were interested in examples of best practices in the usage of Industry 4.0 technologies in order to clearly separate them from the experience of digitalization of supply chains, so we used these works in the development of questionnaires and during interviews conducted for the purposes of this study.

\section{Methodology Implemented}

For the observational data analysis a qualitative approach was applied. Five qualitative interviews (presenters of 5 different companies' profiles that called in this research as "Sport brand", "Outdoor brand", "Fashion brand", "Healthcare brand" and "Apparel brand") gathered the analytical evidence from 236 semi-structured open interviews and surveys. This approach helps to consider more fully how they perceive and understand digital transformation. The details of the interviewed experts is shown in Table 1.

Thus, fresh knowledge and thinking from our respondents have been made possible. In a brief interview guide, each of the interviewees had a short description of the subjects and keywords. Findings suggest that the interviewee has some time to immerse in the topic and some time for thinking and probably offering new perspective. The interviewees were told at the beginning of each meeting of the intent and how to use the gathered information. They also were assured that neither their real name nor the name of the business will be revealed in any manner contrary to ethical principles.

For data collection and then data analysis, a questionnaire for a certain number of participants should be distributed using the SPSS statistical methodology for analytical proof of the research hypotheses.

Regression is an inferential statistical test that analyzes the data gathered and validates the findings of the study on the basis of a 5 percent margin of error. However, 236 participants were distributed, 162 participants addressed the survey and the findings will be disclosed as follows:

- There is a significant relationship among Digitalization and Supply chain performance since the margin error is 0.039 which is lower than 0.05 ;

- There is a significant relationship among I4.0 technologies and Supply chain performance since the margin error is 0.041 which is lower than 0.05 .

Thus, the following hypotheses could be validated:

H1: There is statistical evidence of a relationship between digitalization and supply chain performance - Accepted.

H2: There is no statistical evidence of a relationship between technology and supply chain performance - Rejected.

Table 1. Demographic and professional characteristics of the interviewed experts (compiled by the authors).

\begin{tabular}{|c|l|l|c|c|}
\hline \multicolumn{2}{|l}{} & $\begin{array}{c}\text { Russian } \\
\text { presenters }\end{array}$ & $\begin{array}{c}\text { Thai } \\
\text { presenters }\end{array}$ \\
\hline \multirow{2}{*}{1} & \multirow{2}{*}{ Gender } & Male & 72 & 81 \\
\cline { 3 - 5 } & & Female & 65 & 18 \\
\hline \multirow{3}{*}{2} & \multirow{3}{*}{ Education level } & Bachelor & 110 & 86 \\
\cline { 3 - 5 } & & Magister (Master) & 24 & 12 \\
\cline { 3 - 5 } & \multirow{2}{*}{3} & Doctoral, post-doc & 3 & 1 \\
\hline & & 5-10 years & 33 & 19 \\
\cline { 3 - 5 } & & $10-20$ years & 96 & 64 \\
\hline
\end{tabular}




\begin{tabular}{|c|c|c|c|c|}
\hline & & $>20$ years & 8 & 16 \\
\hline \multirow{3}{*}{4} & \multirow{3}{*}{ Job position } & consulting & 102 & 73 \\
\hline & & mid manager & 22 & 17 \\
\hline & & top manager & 13 & 9 \\
\hline \multirow{4}{*}{5} & \multirow{4}{*}{$\begin{array}{l}\text { Relations to } \\
\text { business }\end{array}$} & consulter & 12 & 7 \\
\hline & & employee & 114 & 87 \\
\hline & & co-owner & 8 & 4 \\
\hline & & major owner & 3 & 1 \\
\hline \multirow{5}{*}{6} & \multirow{5}{*}{ Area of business } & sport brand & 28 & 18 \\
\hline & & outdoor brand & 20 & 22 \\
\hline & & fashion brand & 23 & 21 \\
\hline & & healthcare brand & 30 & 19 \\
\hline & & apparel brand & 36 & 19 \\
\hline & & Totally surveyed & 137 & 99 \\
\hline
\end{tabular}

\subsection{Multiple Regression Analysis}

Table 2. Results of Regression Analyze (compiled by the authors).

\begin{tabular}{|c|c|c|c|c|}
\hline \multicolumn{5}{|c|}{ Model Summary } \\
\hline Model & $\mathrm{R}$ & $\mathrm{R}^{2}$ & Adjusted $\mathrm{R}^{2}$ & Std Error of the Estimate \\
\hline 1 & $.488^{\mathrm{a}}$ & .446 & .417 & .02414 \\
\hline \multicolumn{6}{|c|}{ a. Predictors: (constant), Digitalization, I4.0 technologies } \\
\hline
\end{tabular}

\begin{tabular}{|c|c|c|c|c|c|}
\hline \multicolumn{6}{|c|}{ Coefficients } \\
\hline \multirow[t]{2}{*}{ Model } & \multicolumn{2}{|c|}{ Unstandardised Coeff. } & \multirow{2}{*}{$\begin{array}{c}\begin{array}{c}\text { Standardised } \\
\text { Coeff. }\end{array} \\
\text { Beta } \\
\end{array}$} & \multirow[t]{2}{*}{$\mathbf{T}$} & \multirow[t]{2}{*}{ Sig. } \\
\hline & $\mathbf{B}$ & Std. Error & & & \\
\hline (Constant) & .027 & .011 & & 2.429 & .025 \\
\hline Digitalization & 289 & .121 & .081 & 2.388 & .039 \\
\hline I4.0 technologies & .282 & .128 & .198 & 2.031 & .041 \\
\hline \multicolumn{6}{|c|}{ a. Dependent variable: Supply chain performance } \\
\hline
\end{tabular}

Thus the following equation can be explained as follows:

$$
Y=A+B X 1+B X 2
$$

Where $\mathrm{Y}=$ dependent variable, $\mathrm{A}=$ constant, $\mathrm{B}=$ coefficient, $\mathrm{X}=$ independent variables.

Their supply chain performance was a strong correlation between digitalization (0.039), and technology, (0.041). The following calculation may be done on the basis of the regression.

\section{Supply chain performance $=0.025+0.039$ (digitalization $)+0.041$ (I4.0 technologies $)$}

This indicated that:

- For every one unit increase in digitalization, the supply chain performance was affected by $3.9 \%$;

- For every one unit increase in I4.0 technologies, the supply chain performance was affected by $4.1 \%$.

The researchers then proved that the other hypotheses of analysis are correct and that the null hypotheses are denied and also researched the relation between the variables if the relation is proportional or inverse. 


\subsection{Pearson Correlations}

Table 3. Results of Pearson Correlation (compiled by the authors).

\begin{tabular}{|l|c|c|c|}
\hline \multicolumn{2}{|c|}{} & Digitalization & I4.0 technologies \\
\hline \multirow{2}{*}{$\begin{array}{l}\text { Supply chain } \\
\text { performance }\end{array}$} & Pearson correlation & 0.699 & 0.632 \\
\cline { 2 - 4 } & Sig. (2-tailed) & .001 & .003 \\
\cline { 2 - 4 } & $\mathrm{N}$ & 162 & 162 \\
\hline
\end{tabular}

The Pearson Correlation test presented was implemented to test the correlations between the variables, and the following results were obtained:

- Digitalization and supply chain performance $=0.699$, thus the higher the digitalization is implemented, the performance will be affected by $69.9 \%$

- $\quad$ I4.0 technologies and supply chain performance $=0.632$. This means the higher the technology is implemented, the performance will be affected by $63.2 \%$

- The Pearson correlation test is structured to determine whether the correlation is positive or negative depending on a statistic defined as the individual coefficient. The regression test just indicates whether the coefficient is connected or not. There are also similar and complementary measures for associations with Pearson and regressive research. In the next part, the factor analysis process, a method that analyzes whether or not the data obtained for the variable is credible based on 0.7. This examination helps the researchers to figure out which problems and variables emerge from some outliers.

\subsection{Factor Analysis}

Table 4. Results of Factor Analyze (compiled by the authors).

\begin{tabular}{|l|c|}
\hline & Reliability \\
\hline Digitalization & .854 \\
\hline I4.0 technologies & .831 \\
\hline Supply chain performance & .808 \\
\hline
\end{tabular}

The study of the component is aimed at determining the quality of the answers in each equation. The collected data associated with this variable are valid if the coefficient has been greater than 0.7 .

The results of the validity of the variables are as follows: Reference to the above analyzes found from the statistical tool SPSS:

- For Digitalization-related questions there is a valid relationship, as the trustworthiness coefficient shows a level of 0.854 ;

- The correlation between I4.0 technologies-related issues is valid because the reliability coefficient is 0.831 which is above 0.7 ;

- For questions of Supply chain performance, there is a valid correlation, given that the reliability coefficient is 0.808 which is above 0.7 .

\section{Main Findings}

This study illustrates the projected impact of digital transformation on the entire supply chain. Implementing digital transformation through the practice of Internet of things and Artificial Intelligence tend to prove that digital transformation is of high importance to the supply chain performance. Furthermore, the research highlighted the barriers which might face the companies while implementing the digital transformation in its supply chain practices. As the result statistically evidenced presence of a relationship between 
digitalization, the Industry 4.0 technologies and supply chain performance. This means that $\mathrm{H} 1$ is accepted and $\mathrm{H} 2$ is rejected.

Companies should recognize the relevance of innovative business models that add value to their product portfolio and enter additional demand platforms and new digital consumers. It is therefore important for the supply chain managers to learn how these digital technologies can be used and how these technologies can be used in their current supply chain processes.

The represents of brands in Russia are more optimistic about the prospects for Industry 4.0 technologies introducing into supply chain in comparison with the Thai ones (the values of the coefficients are 78.4 and 42.1 , respectively), which is generally justified by the larger territory and population of Russia. Industry 4.0 technologies is known to be a solution for some traditional problems with infrastructure, typical for Russia.

Experts pointed out that successful adaptation of Industry 4.0 technologies depends largely on the cyber recourses which confirms the applicability for Russia and Thailand of the conclusions of [25], found that this specifically concerns small and medium enterprises (SMEs) as they do not have the same supply chain recourses as large enterprises. The new design enables SME's to visualize the required cyber resources and the integration process and the transformational roadmap the integration process of Internet of things technologies consolidated in the cyber themes of the future makeup of supply chains.

Most of the examples of successful implementation of technologies in logistics systems were reduced to digitalization, which in recent years, according to the interviewed experts, provided an increase in supply chain performance. However, experts have already mentioned examples of using Artificial Intelligence to solve problems of route optimization, as well as examples of processing Big Data to determine customer needs. All this has been made possible thanks to real-time decision making, given the information gathered in the Cloud computing and Cloud robotics analyzed by the monitor and drives customers' behavior (data trends) for an optimal intelligent demand assessment, as well as effective and efficient input/output processes in logistics [26].

Almost all respondents confirmed the importance of advanced development professions and specialists with relevant competencies in the organization to ensure Industry 4.0 readiness. The most popular answers include: Designer of Innovative Systems; Specialist in the Field of Artificial Intelligence, Big Data Analyst, Expert in Cloud and Fog Computing, Blockchain Programmer; Trendwatcher / Forsiter.

The companies "Apparel Brand" in Russia and "Outdoor Brand" in Thailand were the most ready for Industry 4.0 technologies. Among the most pressing issues for further study by the experts were named: the development of new organizational cultures, norms, policies and techniques to more effectively manage challenges in regulations, intercommunication, interoperability and transparency, among others, which allows us to identify further priority areas of research in the context of the Fourth Industrial Revolution.

\section{Limitations and discussion}

This research should be viewed as an addition to existing studies taking into account the small quantity of up-to-date work undertaken in this area. Interviews with managers may be particularly useful for prospective analysis. But there are still some drawbacks to this review. Due to the limited number of tests, the findings cannot be generalized. Conducting research on the example of other companies and even involving other employees could lead to a change in the results. If the same study was extended to various enterprises in one sector, entirely different results may have be drawn.

In addition, the interview partners have diverse careers and perspectives, all of them in different positions and locations. This results in multiple-faceted responses dependent on 
various expertise and experience. Different interview responses may often differ in terms of digitalization and a clear interpretation of Industry 4.0 technologies.

Another specific of the study is that the companies that took part in it were interested in assessing readiness for Industry 4.0. The pattern of business activity [27] of other brands determined that for contrast, some companies not interested in digitalization and Industry 4.0 as well as do not even intend to carry out a study based on such topics. Since participation in the study for brands was voluntary, then disinterested companies refused to participate in it, although, obviously, they could reduce the readiness rate in the case of the complete sample method usage.

We deliberately did not take into account the number of brands that refused to participate in the study in Russia and Thailand, since their number was approximately the same and the question of the competitiveness of these brands in the market conditions of the Fourth Industrial Revolution without the readiness to transform supply chains is debatable. At the same time, we realize that for many companies, distribution efficiencies improving is relevant due to already traditional technologies based more on digitalization, such as, for example, cross docking [28]. But even in this case, it is necessary to understand that the possibilities of working with Big Data, which are available to the human brain and a specially trained neural network, are already significantly different in favor of the last one. And this gap will only grow with the development of machine learning techniques.

\section{Conclusions and recommendations}

The study showed that investing in and deploying emerging technologies will generate a sustainable competitive advantage for companies through improved access to information, cost reduction, improved product quality, responsiveness and cooperation skills. The digitalization as well as implementation of Industry 4.0 technologies of supply chain management would carry groundbreaking improvements. This paper attempts to highlight some of the issues that stress the importance of the management of the digital supply chain, its challenges and how these challenges can become competitive advantage. We evaluated the impact of digital transformation on supply chain performance and the readiness to implement such technologies in Russia and Thailand, considering the results of a study of five brands.

A combined management of the digital supply chain could significantly promote integration of the supply chain and reduce fragmentation in the industry and also provide a sustainable approach towards digital technologies. By improving Industry 4.0 technologies and growing consumer data access, businesses are trying to enhance their service, pertinence and usability. In order to make a long-term relationship with each client, they strive to increase supply chain performance. The company's challenge was to adapt a specific deal to the client. The usage of consumer knowledge is a valuable method in the development and management of sustainable client interactions with most organizations. The main element to a loyal partnership is to remain relevant in contact with the client irrespective of the medium.

Digitalization and Industry 4.0 technologies implementation have been shown to provide an efficient contribution to enhancing business efficiency and productivity. The research assesses the effect of electronic business within the supply chain and offers information on how the potential of Industry 4.0 in the management of supply chain can be used. The issues of managing organizations in conditions of high readiness for the Fourth Industrial Revolution require further study. 


\section{References}

1. S. Saengchai, K. Jermsittiparsert, International J. of Innovation, Creativity and Change 8(8), 103-121 (2019)

2. D. Ivanov et al., Annual Reviews in Control 46, 134-147 (2018)

3. S. Saengchai, K. Jermsittiparsert, International J. of Supply Chain Management 8(5), 733-744 (2019)

4. B. Tjahjono et al., Procedia Manufacturing 13, 1175-1182 (2017)

5. E. Dudukalov et al., Contemporary Economics 10(4), 299-310 (2016)

6. S. Dutta, B. Lanvin, The Network Readiness Index (2020) https://networkreadinessindex.org/wp-content/uploads/2020/11/NRI-2020-V8_28-112020.pdf

7. E. Manavalan, K. Jayakrishna, Computers \& Industrial Engineering 127, 925-953 (2019)

8. M. Mubarik et al., J. of Cleaner Production 292 (2021)

9. R. Stechow, M. Mißler-Behr, The EUrASEANs: J. on Global Socio-Economic Dynamics 6(7), 51-57 (2017)

10. T. Hayhoe et al., J. of Self-Governance and Management Economics 7(2), 31-36 (2019)

11. E. Nica, J. of Self-Governance and Management Economics 7(3), 27-33 (2019)

12. B. Esmaeilian et al., Resources, Conservation and Recycling 163 (2020)

13. L. Li, Systems Research and Behavioral Science 37(4), 579-592 (2020)

14. D. Ushakov et al., J. of Advanced Research in Law and Economics 10(8), 2566-2573 (2019)

15. K. Hobusch, M. Mißler-Behr, The EUrASEANs: J. on Global Socio-Economic Dynamics 5(6), 40-47 (2017)

16. Y. Chong, C. Chen, International J. of Advanced Manufacturing Technology 48(1-4), 395-406 (2010)

17. A. de Carolis et al., IFIP International Conference on Advances in Production Management Systems, 13-20 (2017)

18. S. Nadella, J. Euchner, Research-Technology Management 61(4), 11-15 (2018)

19. B. Gates, Lean Manufacturing in the Age of the Industrial Internet. Supply \& Demand Chain Executive (2014) https://www.sdcexec.com/sourcingprocurement/article/12019013/lean-manufacturing-in-the-age-of-the-industrial-internet

20. A. Glas et al., International J. of Business and Management Invention 5(6), 55-66 (2016)

21. N. dos Santos et al., IFIP Advances in Information and Communication Technology 591 (2020)

22. E. Dudukalov et al., E3S Web of Conferences 217, 03004 (2020)

23. K. Markov, P. Vitliemov, IOP Conference Series: Materials Science and Engineering 878, 012047 (2020)

24. S. Kumar et al., J. of Cleaner Production 293, 126023 (2021)

25. P. Radanliev et al., Cybersecurity 3(1), 13 (2020)

26. C. Garay-Rondero et al., J. of Manufacturing Technology Management 31(5), 887-933 (2019) 
27. T. Kushnarenko et al., European Research Studies J. 21, 553-563 (2018)

28. E. Dudukalov et al., IOP Conference Series: Materials Science and Engineering 918, 012188 (2020) 